\title{
The Construction of the Dolphinarium Building in the Seismic Area
}

Mazhiev Kh.N.

Faculty of Construction of Grozny State Oil Technical

University named M.D. Millionshchikova

Department of Materials Science,

Complex Research Institute named Kh.I. Ibragimov of

Russian Academy of Sciences,

Department of Technical Sciences

Academy of Sciences of the Chechen Republic

Grozny, Russia

seismofund@mail.ru

Mazhiev K.Kh.

Faculty of Construction ofGrozny State Oil Technical

University named M.D. Millionshchikova,

Department of Materials Science

Complex Research Institute named Kh.I. Ibragimov of

Russian Academy of Sciences,

Faculty of Public Administration

Chechen State University

Grozny, Russia

m.k.kh@mail.ru

Mazhieva A. Kh.

The Faculty of Construction of Grozny State Oil Technical

University named M.D. Millionshchikova

Grozny, Russia

a.mazhieva@mail.ru

Mazhiev Adam Kh.

Department of Materials Science

Complex Research Institute named Kh.I. Ibragimov of

Russian Academy of Sciences,

Department of Technical Sciences

Academy of Sciences of the Chechen Republic

Grozny, Russia

adammazhiev@mail.ru

\author{
Batayev D. K-S. \\ Department of Materials Science
}

Complex Research Institute named Kh.I. Ibragimov of

Russian Academy of Sciences,

Department of Technical Sciences

Academy of Sciences of the Chechen Republic

Faculty of Construction of Grozny State Oil Technical

University named M.D. Millionshchikova

Grozny, Russia

kniiran@mail.ru

Radnaev O.B.

Enterprise for Architectural and Construction Design,

Construction and Reconstruction of

Capital Construction Projects

Moscow, Russia

o.radnaev@psrrf.ru

Kadiev S.Z.

State Unitary Enterprise "Chechengrazhdanproekt"

Grozny, Russia

chgproekt@mail.ru

\author{
Mazhiev Aslan Kh. \\ Department of Materials Science \\ Complex Research Institute named Kh.I. Ibragimov of \\ Russian Academy of Sciences, \\ Department of Technical Sciences \\ Academy of Sciences of the Chechen Republic, \\ Faculty of Public Administration \\ Chechen State University \\ Grozny, Russia \\ aslanmazhiev@mail.ru
}

\footnotetext{
Abstract-The article presents the results of research aimed at scientific and technical justification of design solutions underlying the design of the building of the dolphinarium constructed in a seismic area. The findings include the effective technical solutions based on the use of modern composites and traditional materials that guarantee the reliable operation of the bearing structures of the building in conditions of high seismic hazard.
}

Keywords-construction design, reinforced concrete, construction, calculation, displacement, load, reliability, seismicity, dolphinarium

\section{INTRODUCTION}

The analysis of literature and information sources shows that currently, in seismic areas of Russia, the construction of entertainment complexes including dolphinariums is actively developing. Dolphinarium is a unique entertainment and 
health facility, where dolphins are kept for the purpose of studying, training, showing to visitors, dolphin therapy, etc.

The dolphinarium with the capacity of 500 seats was built in Grozny. It borders with a green park having the entertainment facilities with the total area of 55 hectares.

The green park provides attractions and places to relax. There are playgrounds, a children's railway, riding areas, walking trails, entertaining water channels and a pond for children and adults. In addition, the park houses street attractions for children, walking areas and alleys. Family and extreme entertainment facilities are under construction.

\section{Methods AND MATERIALS}

In order to determine the basic design parameters of the bearing structures of the building of the dolphinarium in Grozny, the software design complex "Lira CAD PRO" performed the calculation of the main and special combination of loads $[1,3,5,7]$.

The calculation of the main combination of loads, all weight loads (constant, temporary, short-term) was performed with a combination factor of $\Psi_{1}=\Psi_{2}=1$. Wind loads were not taken into account. Load reliability coefficients are culculated in accordance with table 1 .

When calculating a particular combination of loads (including seismic effects), the constant loads are estimated with the factor combinations of 0.9 ; temporary long -0.8 , and short-term (on the floor/ceiling intermediate slab panel and coverage) -0.5 . In addition, the seismic loads were estimated to be the ratio of the combination equal to one.
The calculation of bearing structures and design decisions were made on the basis of the following regulations and initial data:

- The National Standard (GOST P 54257-2010 "Reliability of Building Structures and Bases. Basic Provisions and Requirements");

- Construction Rules (20.13330.2011 "Construction Rules and Regulations 2.01.07-85*" Loads and impacts");

- Construction Rules (14.13330.2014 "Construction Rules and Regulations II-7-81* "Construction in Seismic Areas");

- The report on engineering-geological surveys for the development of project documentation at the facility "Construction of an Amusement Park in the Village of Chernorechye, Factory District, Grozny, The Chechen Republic"(LLC “Archon-Crimea”);

- The layouts of the Architectural Section.

The degree of responsibility for the building was estimated as 1B (high level of responsibility) in accordance with the instructions of paragraph 9.1 of The National Standard (ГОСТ P 54257-2010). In calculation of supporting structures and bases, the safety factor on liability $\gamma_{\mathrm{n}}$, is assumed to be 1.1 that is in accordance with Table 2 and the National Standard (GOST P 54257-2010).

The service life of the main bearing structures of the building is at least 100 years.

TABLE I. CONSTANT AND PROLONGED PRESSURE ON A HORIZONTAL LOAD-BEARING ELEMENTS OF THE BUILDING (FLOORS/CEILING SLAB PANELS, COATINGS) BY WEIGHT OF THE FLOORS AND FILLINGS AND THE SAFETY FACTORS FOR THE LOAD

\begin{tabular}{|c|c|c|c|c|c|c|}
\hline $\begin{array}{c}\text { Item } \\
\text { number }\end{array}$ & The name of the load & $\begin{array}{l}\text { Thickness, } \\
\text { m }\end{array}$ & $\begin{array}{c}\text { Volumetric } \\
\text { weight, } \\
\gamma, \mathbf{t} / \mathbf{m}^{3} \\
\end{array}$ & $\begin{array}{c}\text { Normative } \\
\text { value, } \\
g_{n}, \mathbf{t} / \mathbf{m}^{2}\end{array}$ & $\begin{array}{c}\text { The safety } \\
\text { factor for } \\
\text { load } \gamma_{\mathrm{f}}\end{array}$ & $\begin{array}{c}\text { Calculated } \\
\text { value, } \\
\mathrm{g}_{\mathrm{p}, \mathrm{t}} \mathrm{t} / \mathbf{m}^{2} \\
\end{array}$ \\
\hline 1. & Own weight of monolithic reinforced concrete structure & - & 2.5 & - & 1.1 & 2. \\
\hline 2. & Own weight of the wooden roof structures & - & 0.5 & - & 1.1 & 0.55 \\
\hline 3. & $\begin{array}{l}\text { The weight of the floor construction above the } \\
\text { foundation slab }\end{array}$ & 0.08 & 1.8 & 0.144 & 1.3 & 0.187 \\
\hline 4. & $\begin{array}{l}\text { Weight of floor construction on the floor slab above the } \\
\text { basement }\end{array}$ & 0.08 & 1.8 & 0.144 & 1.3 & 0.187 \\
\hline 5.1 & Cross plank covering & 0.08 & 0.5 & 0.04 & 1.1 & 0.044 \\
\hline 5.2 & Rockwool RUF BATTS D Extra & 0.2 & 0.235 & 0.05 & 1.2 & 0.06 \\
\hline 5.3 & Membrane coating & & & $1.1 \mathrm{~kg} / \mathrm{m}^{2}$ & 1.1 & $1.21 \mathrm{~kg} / \mathrm{m}^{2}$ \\
\hline
\end{tabular}

Loads from the weight of the floors are set in the LIRACAD environment. The own weight of structures (item 1, table. 2) is set using the LIRA-CAD function "Add own weight" with the appropriate indication of the volume weight of structures when specifying the stiffness characteristics of the elements.

Loads from the weight of the floor structures (coating) are given for the calculation scheme uniformly distributed load on the floor, $\mathrm{t} / \mathrm{m}^{2}$. The loads from the partitions are taken by the actual position of the strip load:

- For walls with a thickness of $120 \mathrm{~mm}$, the linear load is $1.27 \mathrm{t} / \mathrm{m}$;
- For partitions with a thickness of $200 \mathrm{~mm}$, the running load is $2.3 \mathrm{t} / \mathrm{m}$.

TABLE II. NORMATIVE VALUES OF VARIABLE LOADS ON THE CEILING/FLOOR INTERMEDIATE SLAB (COATING) AND SAFETY FACTORS LOAD

\begin{tabular}{|l|c|c|c|}
\hline \multicolumn{1}{|c|}{ The name of the load } & $\begin{array}{c}\text { Normative } \\
\text { value } \\
\mathbf{g}_{\mathbf{n}, \mathbf{t} / \mathbf{m}^{2}}\end{array}$ & $\begin{array}{c}\text { The safety } \\
\text { factor for } \\
\text { load } \boldsymbol{\gamma}_{\mathbf{f}}\end{array}$ & $\begin{array}{c}\text { Calculated } \\
\text { value } \\
\mathbf{g}_{\mathbf{p}}, \mathbf{t} / \mathbf{m}^{\mathbf{2}}\end{array}$ \\
\hline $\begin{array}{l}\text { Floor slab panel of administrative } \\
\text { and household premises }\end{array}$ & 0.20 & 1.2 & 0.220 \\
\hline $\begin{array}{l}\text { Stairs, halls, corridors, foyer, terraces } \\
\text { (p. 12A) }\end{array}$ & 0.4 & 1.2 & 0.48 \\
\hline Tribunes & 0.5 & 1.2 & 0,6 \\
\hline Snow load* & 0.084 & & 0.12 \\
\hline
\end{tabular}


The safety factors for the load and the normative value of temporary loads are taken in accordance with table 8.3 Construction Rules (SP 20.13330.2011). The value of snow load (*) given in the table is the load with the coefficient of transition from weight of snow cover of the ground to snow load on a covering of $\mu=1$ accepted according to paragrph 10.4 of Construction Rules (SP 20.13330.2011).

The values of the coefficient $\mu$ in the computational scheme is in accordance with the instructions of paragraph 10.4 Construction Rules (CП 20.13330.2011) in Appendix D. The following values of $\mu$ were used for this calculation scheme:

- According to the first embodiment, across the roof $\mu_{1}=1$ (figure G. 13 in Appendix $G$ of Construction Rules (SP 20.13330.2011));

- According to the second embodiment, $\mu_{2}=2.45$

- On the coating area with a lantern, $\mu=2.5$ (scheme G. 8).

The calculation of seismic loads is made in accordance with the requirements of "Construction in Seismic Areas". In case of seismic effects (specific combination), the calculated loads are made in accordance with the above combination coefficients $[6,12,13]$.

For calculations of seismic effects we used the ratios of Construction Rules (CП 14.13330.2014):

$-\mathrm{K}_{0}=1.5$ - the coefficient, taking into account the purpose of the structure and its responsibility (table.3, based on DLE);

- $\mathrm{K}_{1}=0.35$ - the coefficient considering the allowed damages of buildings and constructions (tab.4) under seismic load along the Y-axis;

- $\mathrm{K}_{1}=0.3$ - the coefficient taking into account the allowed damages of buildings and constructions (tab.4) at seismic load on the X-axis;

- $\mathrm{A}=4.0 \mathrm{~m} / \mathrm{s}^{2}-$ acceleration value at the ground level;

$-K_{\psi}=1.3-$ the coefficient taken from table. 5 (for seismic loads on the $\mathrm{Y}$-axis);

$-K_{\psi}=1.3-$ the coefficient taken from table. 5 (for seismic loads on the $\mathrm{X}$-axis)

- Category of soil seismic properties - II.

- Estimated seismicity of the building - 9 points.

Taking into account the architectural and space-planning solutions of the building together with the high seismic activity of the construction area ( 9 points), the calculation were performed according to the frame-coupling design scheme that provides reliable perception of operational and horizontal seismic loads (Fig. 1).

Figure 2 shows the finite element model of the building of the dolphinarium. As a result of the performed calculations, we obtain the vertical displacements from static (Fig. 3), the horizontal displacement from seismic loads along the x-axis (Fig. 4), the horizontal displacement from seismic loads along the $Y$ axis (Fig. 5)

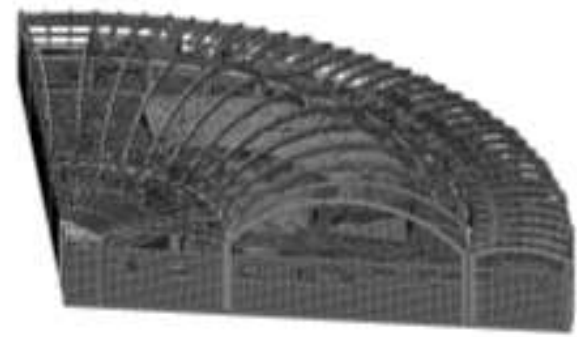

Fig. 1. A design scheme of the building of the dolphinarium.

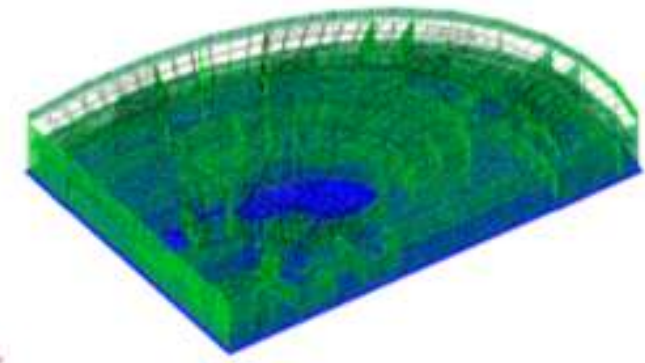

Fig. 2. Finite element model of the dolphinarium building

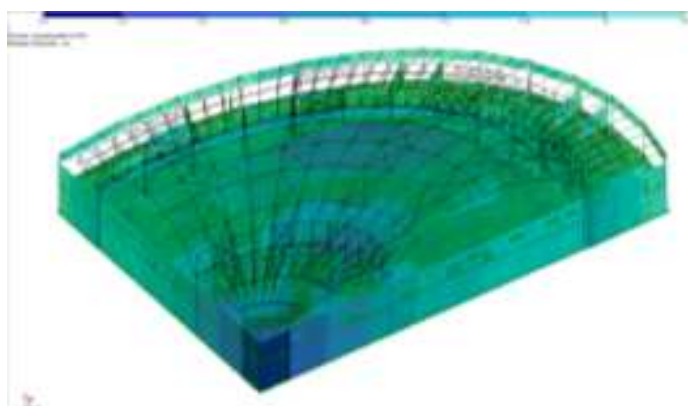

Fig. 3. Vertical movements of the building from static loads.

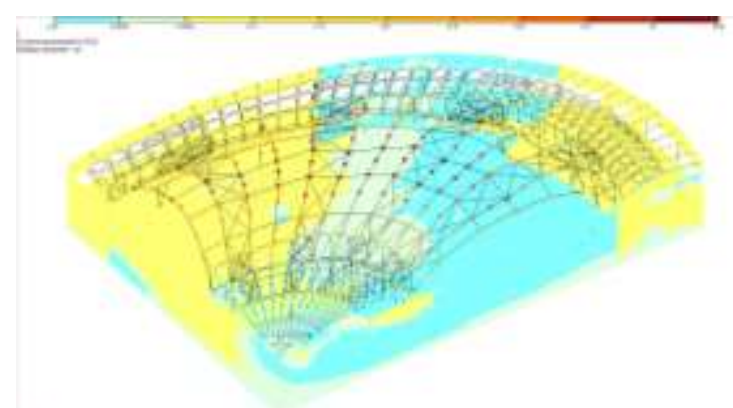

Fig. 4. Horizontal movement along the $\mathrm{X}$-axis from seismic loads.

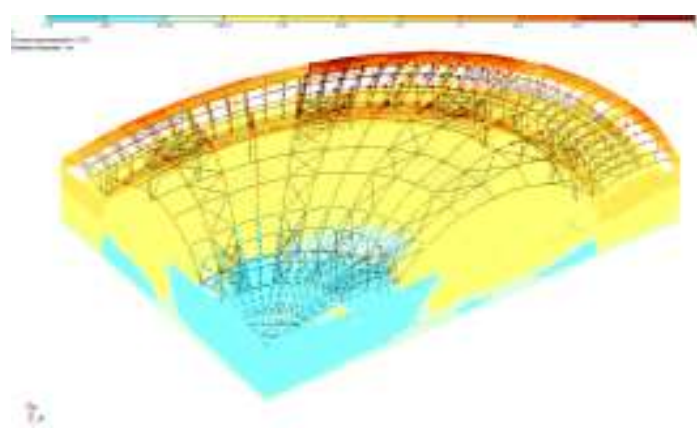

Fig. 5. Horizontal Y-axis movements from seismic loads. 
The building is divided by expansion joints into 4 blocks (Fig. 6).

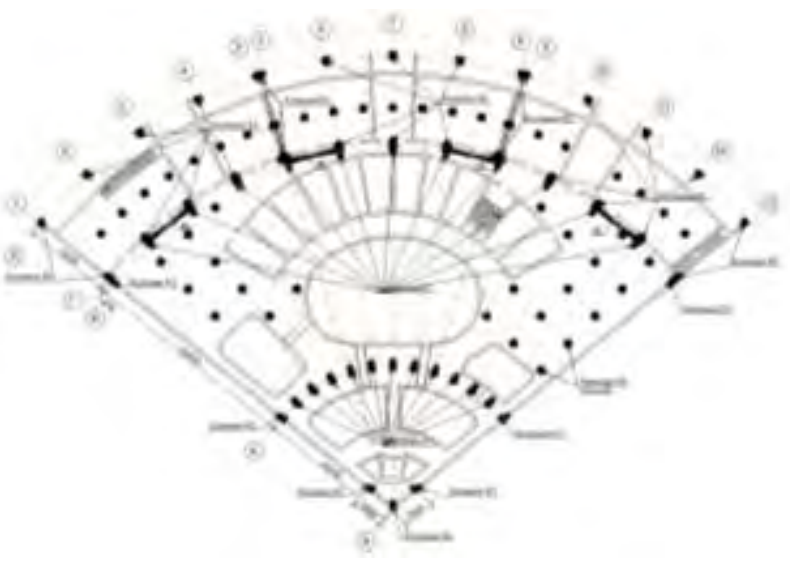

Fig. 6. Scheme of the main load-bearing structures (marking of columns).

In order to limit the rolls and uneven sediment of the building,we used a solid monolithic reinforced concrete slab foundation with a thickness of $700 \mathrm{~mm}$. For the foundation slab we used concrete (class B25), reinforcement of individual rods (class A500C). The coefficient of reinforcement is not less than $-0.15 \%$. The determination of forces in the base slab and its deformation were performed in accordance with the requirements of Construction Rules SP 22.13330.2011. The deformations of the bases were determined by the calculation of the conditions of joint work of the superstructure, the foundation, and the base.

Gravel-pebble soils with a deformation modulus of 47 $\mathrm{MPa}$ and a design resistance of $4.0 \mathrm{kgf} / \mathrm{cm}^{2}$ are accepted as a natural base for the base plate. It should be noted that for the foundation slab of the building, a limited crack opening (category 3, partially compressed elements that perceive the pressure of liquids) are allowed, with the width of a short crack $a_{c r c l}=0.3 \mathrm{~mm}$, and for a long crack $a_{c r c 2}=0.2 \mathrm{~mm}$.

Monolithic reinforced concrete structures with flexiblereinforcement are used as the main load-bearing structures. Based on the results of the calculation, for loadbearing structures, we used the concrete (class B25) with the reinforcement bar (class A500C). The thickness of the walls is $400 \mathrm{~mm}$, except for the first floor walls. The thickness of the walls of the first floor $-300 \mathrm{~mm}$. The columns have a square section of $500 \times 500 \mathrm{~mm}$ (in the basement), the t-section-the height of the ribs $1400 \mathrm{~mm}$, $1000 \mathrm{~mm}$, the thickness of the ribs $500 \mathrm{~mm}$. Vertical connections between the columns are made from gantry angle corners (Fig. 7). Rigid frames (columns t-section and the beam-wall height of $1700 \mathrm{~mm}$ and thickness of $25 \mathrm{~mm}$, Fig.8) perceive the horizontal loads $[2,4,9,10,11]$.

The intermediate slab and slab under the tribune are with a thickness of $250 \mathrm{~mm}$ concrete (class B25) with a separate reinforcement bars of A500C class. For the intermediate slab of the building there is a limit by the width crack opening (category 3 , indoors) for a short crack $a_{c r c l}=0.4 \mathrm{~mm}$, and for a long crack $a_{c r c 2}=0.3 \mathrm{~mm}$.

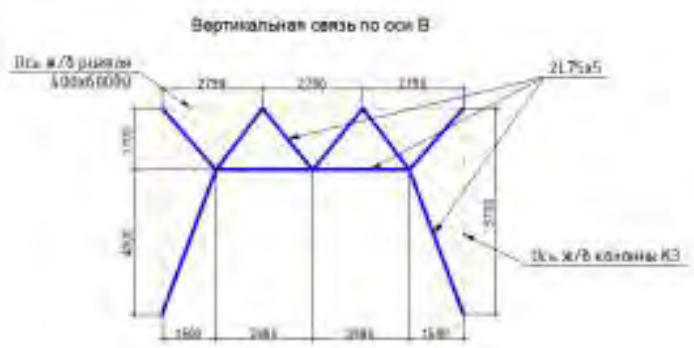

Fig. 7. Vertical connection of the columns.

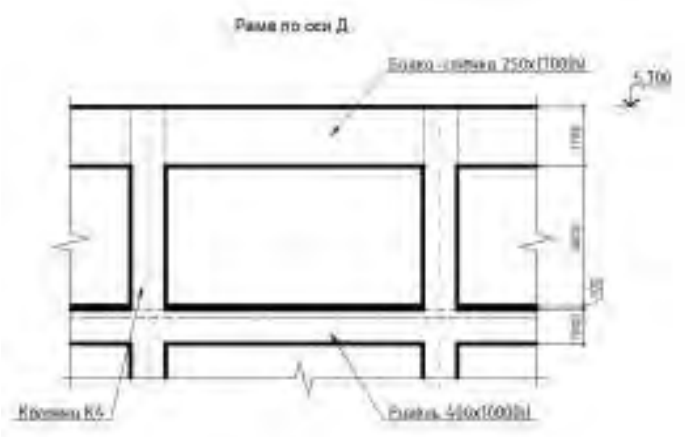

Fig. 8. Scheme of rigid frame, perceiving horizontal loads.

The coating of the building is made of laminated wood [8]. The main structures of the coating are:

- statically determined beams with compensatory junctions without a dual-section $140 \times 1000 \mathrm{~mm}$ curved upward, pivotally supported by the column;

- statically definable three-hinged arches of circular shape with cross section $140 \times 1000 \mathrm{~mm}$ having the crescent shape with the transfer of pressure on concrete columns (Fig. 9);

- triangle farms with diagonal lattice $(140 \times 350 \mathrm{~mm})$ and curved belts $140 \times 400 \mathrm{~mm}$. The farms fixedly rely on concrete columns and on concrete beam; the nodes are loadbearing structures made according to system proposed by the Central Scientific Research Institute for Building Structures.

Over the load-bearing structures of the coating there are add-ins of wooden elements with cross-section of 140x400 $\mathrm{mm}$ for the roofing.

Between the supporting structures, with the intervals of $6 \mathrm{~m}$, there are wooden struts. Between the struts and the bearing structures, there are four connection blocks in the form of cross ties made from round steel. The upper zones of the add-in also have a second tier of links. There are vertical cross-links between the superstructures (Fig. 9).

The spans are designed as carvings spaced at intervals of $1.5 \mathrm{~m}$ in the same level with the top of the supporting structures. 
The covering is combined from a double cross flooring from $40 \mathrm{~mm}$ boards with a plate mineral wool heater and a layer of rigid mineral wool plates with a roof in the form of a light membrane.

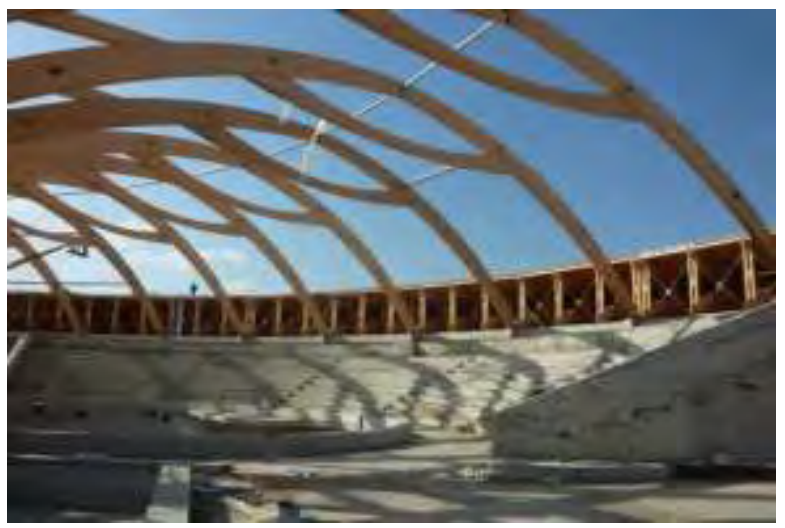

Fig. 9. Fully articulated arch of crescent shape and the vertical cross connection between the struts.

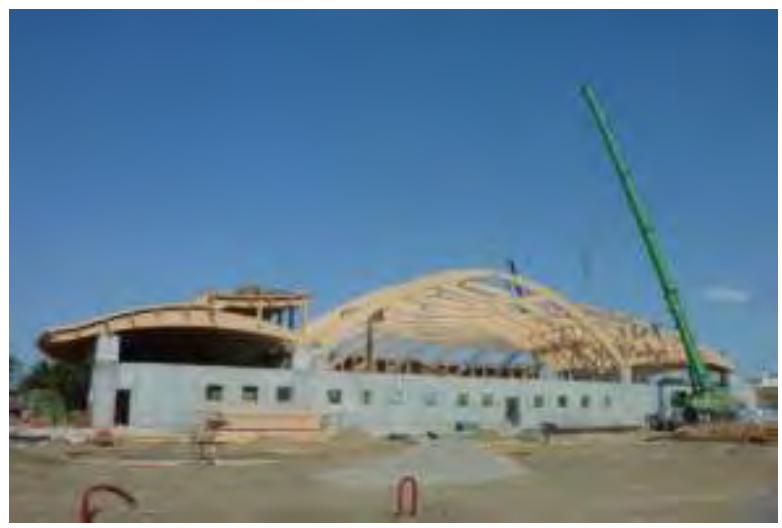

Fig. 10. General view of the object under construction

The following types of loads were taken into account when performing the calculations for the main and specific combination:

1. Constant load-own weight of bearing structures of the building;

2. Constant load - weight of the floor structure (roof), enclosing walls, partitions, finishing;

3. Temporary long-term load on the floor in all spans according to the functional purpose of the premises in the building;

4. Temporary short-term load on the floors in all spans according to the functional purpose of the premises in the building;

5. Snow load on building surfaces;

6. Seismic load in the $X O Y$ plane along the global $X$-axis of the design scheme (along the alphabetic axes of the building) - dynamic load;
7. Seismic load in the $X O Y$ plane along the global $Y$-axis of the design scheme (along the digital axes of the building) - dynamic load;

8. The soil pressure on basement walls;

9. Water pressure on the pool walls.

The determination and evaluation of the main controlled parameters of displacements and deformations of the computational model of displacements were carried out according to the given calculated load combinations:

- all vertical static loads determining the pressure in the soil under the sole of the foundations, sediment and roll of the foundation slab and deflections of the intermediate slab and coating elements;

- all vertical static loads with combination coefficients and seismic loads determining horizontal displacements (and assessing the effect of rotation angles) of compartments;

Unprofitable combinations of loads for reinforced concrete structures are determined by the functional PC Lira-CAD-Calculated Combination of Forces.

\section{RESULTS}

According to the results of the complex design testing of bearing structures of the building we found out the following:

1. The calculated maximum displacement of the top of the blocks with a special combination of loads is $35 \mathrm{~mm}$, which does not exceed, with the sum of two amplitudes, adopted antiseismic seam between blocks $100 \mathrm{~mm}$.

2. The maximum estimated sediment base slab is $25.2 \mathrm{~mm}$.

3. The stress in the ground base under the sole of the foundation to $1.63 \mathrm{~kg} / \mathrm{cm}^{2}$, which does not exceed the calculated resistance of the base ground $4.0 \mathrm{~kg} / \mathrm{cm}^{2}$.

4. The estimated required area of the reinforcement of the lower zone of the foundation slab along the $X$ and $Y$ axes is $40.2 \mathrm{~cm}^{2} /$ lin. $\mathrm{m}$.

5. The estimated required area of the reinforcement of the upper zone of the foundation slab along the $X$ and $Y$ axes is $12.7 \mathrm{~cm}^{2} / \mathrm{g} . \mathrm{m}$ and $19.0 \mathrm{~cm}^{2} /$ lin. $\mathrm{m}$, respectively.

6. The estimated required area of the reinforcement of the lower zone of the intermediate slab at the level of 0.000 along the $X$ and $Y$ axes is $50.9 \mathrm{~cm}^{2} /$ lin. $\mathrm{m}$;

7. The estimated required area of the reinforcement of the upper zone of the intermediate slab at the level of 0.000 along the $X$ and $Y$ axes is $24.5 \mathrm{~cm}^{2} / \mathrm{lin}$. $\mathrm{m}$ and 30.8 $\mathrm{cm}^{2} /$ lin. m, respectively.

8. The reinforcement peaks in the floor/ceiling intermediate slab occur at the columns along the $B$ axis. To relieve stress in the slab in these places, it is recommended to add beams. 
9. Longitudinal forces up to $146 \mathrm{t}$., arising in the crossbars at the level of +5.700 in $A$-axis are difficult to implement in a constructive respect, so it is recommended to take a solid monolithic reinforced concrete slab at the top level of the crossbars.

10. The estimated required area of longitudinal reinforcement of the columns of $500 \times 500 \mathrm{~mm}$ is 13.0 $\mathrm{cm}^{2}$.

11. The estimated required area of longitudinal reinforcement of the $t$-section columns along the $B$-axis is $79.8 \mathrm{~cm}^{2}$ vertically and $18.8 \mathrm{~cm}^{2}$ horizontally.

12. The estimated required area of longitudinal reinforcement of the t-section columns along the $C$-axis is $116.0 \mathrm{~cm}^{2}$ vertically, $44.4 \mathrm{~cm}^{2}$ horizontally.

13. The estimated required area of longitudinal reinforcement of the t-section columns along the $D$-axis is $39.9 \mathrm{~cm}^{2}$ vertically, $37.2 \mathrm{~cm}^{2}$ horizontally.

14. The estimated required area of longitudinal reinforcement of the t-section columns along the $D$-axis is $42.1 \mathrm{~cm}^{2}$ vertically, $34.2 \mathrm{~cm}^{2}$ horizontally.

\section{CONCLUSION}

Thus, the performed calculation analysis allowed us to justify the choice of frame-coupling design scheme, providing the possibility of reliable perception of operational and seismic loads. The structural solutions made for the construction of the building provide both the required level of reliability during the period of operation according to the criteria of I and II groups of states limits under the action of the main combination of loads, and the necessary strength reserve under the action of loads of a specific combination.

\section{References}

[1] Kh.N. Mazhiev, D.K-S. Bataev, M.A. Gaziev, and K.Kh. Mazhiev. Materials and structures for construction and restoration of buildings in seismic areas. Grozny, 2014.

[2] D.K.S. Bataev, M.A. Gaziev, A.Kh. Mazhiev, and A.Kh. Mazhiev, "Investigation of the Properties of New Surface-Active Additives for Concretes", Materials Science Forum, vol. 931, pp. 544-547, 2018.

[3] V.E. Bogovis, and R.Yu. Vodopyanov, "The software package Lira 9.6 for automated calculation and design of structures", Industrial and Civil Engineering, No 4, pp. 59-60, 2009.

[4] P.P. Polskaya, and D.R. Mailyan, "Composite materials as the basis of efficiency in construction and reconstruction of buildings and structures", Don Engineering Bulletin, No. 4-2 (23), pp. 162, 2012.

[5] S.I. Merkulov, and N.V. Polyakova, "Designing for possible progressive deformation - the ensuring of structural safety in an emergency", Auditorium, 4 (12), pp. 73-78, 2016.

[6] T.A. Belash, "The specific features of construction and operation of earthquake-proof buildings", Proceedings of St.Petersburg Transport University, 4 (17), pp. 5-16, 2008.

[7] Yu.P. Nazarov, Yu.N. Zhuk, V.N. Simbirkin, "Automated calculation of bearing structures of buildings", Industrial and Civil Engineering, No. 8, pp. 42-44, 2006.

[8] Yu.P. Nazarov, S.B., Turkovsky, A.A. Pogoreltsev, "Efficiency of bearing glued timber structures in seismic areas", Structural Mechanics and Calculation of Structures, 6 (227), pp. 36-40, 2009.

[9] H.H. Trekin, and E.N. Kodysh, "The prospects of application of highstrength concrete in the construction of buildings and structures", Bulletin of MSCU, vol. 2-1, pp. 39-43, 2011.

[10] S.S. Kaprielov, and I.A. Chilin, "Uultra-high-strength self-compacting fibro-concrete for monolithic structures", Bulletin of the Construction Research Centre, No 1 (12), pp. 14-22, 2017.

[11] S. Kaprielov, S. Goldenberg, and A.G. Tamrazyan "On the selfdestruction of high-strength concrete, subjected to cyclic freezing", News of Higher Educational Institutions, Technology of Textile Industry, No 5 (371), pp. 56-61, 2017.

[12] A.D. Abakarov, and I. B. Kurbanov "On the assessment of seismic risk of territories", Bulletin of the Dagestan State Technical University, Engineering Sciences, No 1 (32), pp. 68-76, 2014.

[13] O.V. Mkrtychev, G.A. Dzhinchvelashvili, and M.S. Busalova, "Calculation of a multi-storey monolithic concrete building on the earthquake in nonlinear dynamic formulation", Procedia Engineering, vol. 111 , pp. 545-549, 2015. 